\title{
Epidemiological survey of fluorosis in a village of Bastar division of Chhattisgarh state, India
}

Context: Fluorosis is an important public health problem in few pockets of some states of India. Aim: The aim was to study the prevalence of fluorosis, mapping the deformities, the type and severity of deformities and to assess the fluoride concentration in prime drinking water sources in the Dimrapal village of Bastar region. Materials and Methods: A cross-sectional study of the Dimrapal village was done by door to door visit and on-site clinical examination of the study population was carried out. This was followed by collection of drinking water samples in selected paras for estimating fluoride levels. Statistical Analysis Used: Analysis was done using prevalence rate, Chi-square test, mean and standard deviation. Results: Overall prevalence of fluorosis cases was found to be $23.10 \%$. The prevalence of dental fluorosis was $12.6 \%$ that of skeletal fluorosis was $28.8 \%$, and the combined prevalence of dental and skeletal fluorosis was $1.8 \%$. Dental fluorosis was found to be very common in children and teenagers. Skeletal fluorosis was found to be more common in age group above 45 years, however, it was lower in the children's (6-12) irrespective of the gender. The fluoride level in surveyed ground water sources from various para ranged from 0.1 to $7.30 \mathrm{ppm}$.

Key words: Dental fluorosis, genu varum, genu vulgum, prevalence, skeletal fluorosis

\section{Sunil Vilasrao Gitte, Ramanath Sabat, Krishnamurthi Kamble}

Regional Office of Health and Family Welfare and Regional Leprosy Training and Research Institute, Under Ministry of Health and Family Welfare, Govt of India,

Raipur, Chhattisgarh, India

Address for the Correspondence: Dr. Sunil Vilasrao Gitte, Deputy Director, Regional Office of Health and Family Welfare and

Regional Leprosy Training and Research Institute, Under Ministry of Health and Family Welfare, Govt of India, Lalpur, Raipur - 492 001, Chhattisgarh, India. E-mail: sv.gitte@gov.in

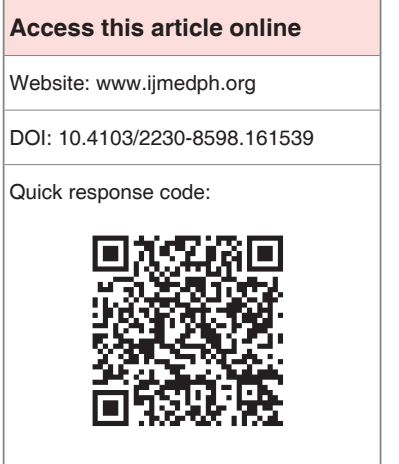

\section{INTRODUCTION}

Fluorosis is a disease caused by deposition of fluorides in the hard and soft tissues of the body. It is not merely caused by excess intake of fluoride, but also related to other attributes and variables which determine the onset of fluorosis in human population. Many studies have reported the endemicity of fluorosis in this geographic area where the fluoride content in drinking water is high. ${ }^{[1]}$ Various states have reported endemic fluorosis in India. ${ }^{[2]}$ About 62 million people, including 6 million children are at risk in India suffering from dental, skeletal and/or nonskeletal fluorosis. ${ }^{[3]}$ Fluoride level of $>1.5 \mathrm{mg} / \mathrm{l}$ in drinking water is considered to be hazardous to health and manifest in the form dental and skeletal fluorosis. ${ }^{[4]}$ The disease may occur in an individual at sub-clinical, chronic or acute levels of manifestation. Crippling skeletal fluorosis can occur when fluoride content of water is very high (>2-3 ppm) or even at very low (lower than $1 \mathrm{ppm}$ even at $0.7 \mathrm{ppm}$ ). ${ }^{[5]}$ The severity of fluorosis depends upon fluoride content of drinking water, daily intake of water, continuity and duration of exposure, and climatic conditions. Hence, it is necessary to explore the geographical distribution and present contamination level of water and accordingly developing a strategy for safe drinking water source. Endemic areas have been reported in some pockets of Chhattisgarh, a central Indian state. ${ }^{[6]}$ Present study was carried out as part of disease mapping exercise in selected pocket of a tribal district of Chhattisgarh state with an objective to assess the burden of fluorosis, mapping the deformities and to detect the fluoride concentration in prime drinking water sources.

\section{MATERIALS AND METHODS}

A cross-sectional survey of the Dimrapal village of Jagdalpur district, Bastar Division of Chhattisgarh state was carried out during January 2014. A village map, as per locality was prepared with the help of key informants. The informal meeting was held with Block Medical Officer, Block Extensor Education officer, Auxiliary Nurse Midwifery, Multipurpose worker and village level local leaders. House to house survey of the whole village was undertaken by a team continuously for three days to cover the entire 
population. A follow-up visit was made on the evening of the last day to cover the houses which were found locked and individuals who were absent on the day of the survey. All household members were clinically examined during house to house visit. Data were collected using predesigned, pretested proforma. Field case definitions were used for labeling types of fluorosis.

a. Dental fluorosis: Teeth's exhibits clinical signs of mottled enamel, chalk white, yellowish brown or brownish black streaks over teeth.

b. Genu varum: Outward bowed legs usually around knee in the standing position.

c. Genu valgum: Inward bowing of legs in standing position.

d. Kyphosis: Forward bending of spine, with fixed, rigid thoracic cage.

Identified water samples were collected and labeled on the $2^{\text {nd }}$ day of the survey. Samples were collected in detergent washed bottles from commonly used water source of each para. These water samples were sent to the Public Health Engineering Laboratory at district Durg for estimation of water fluoride levels. After analysis of water samples, a mapping of affected household and fluoride content water source was done in each hamlet of surveyed village. Data were entered in WHO Epi Info (3.5.4) and analysis was done by applying appropriate statistical tests.

\section{RESULTS}

Dimrapal village is situated on a Bakawand block of Bastar district with population 1975. The survey covered 10 paras, of which, two paras are $1-1.5 \mathrm{~km}$ away from the main locality. The female population was more as compared to male (1095:880). During a door to door survey, totally 1674 (85\%) population residing in 291 houses was examined. Ten houses were found to be locked and temporarily remained out of the village on survey dates. Among surveyed population 834 (49.8\%) were females and 840 $(51.2 \%)$ males. Children from primary and secondary schools were separately examined with the help of teachers and local volunteers. The population pyramid of surveyed population had a broad base and tapering apex showing more number of child and younger population. Children below 12 years of age were 464 (27.7\%), and teenagers were $280(16.7 \%)$. The village is split into various paras (local name) according to locality and occupant of the village. Village (Hamlets) was heterogeneous in nature as per income status of occupants and engaged as marginal farmers, agriculture, and nonagricultural labor. $32 \%$ of occupants were engaged in agriculture while $15 \%$ were nonagriculture labor and $28.9 \%$ were students. About $10.6 \%$ population was below 6 years while $2 \%$ were unemployed. Detail information about income of individual members could not be assessed.

Dental fluorosis and genu varum were the most common form of fluorosis in surveyed paras. 29 (7.0\%) persons were suffering from multiple fluorosis deformities ranging from mild to crippling stage. Children were affected by dental fluorosis while adults were affected by skeletal fluorosis. Kyphosis deformity was seen in old age group and younger females. Out of total fluorosis cases $50 \%$ of cases were dental fluorosis, 38\% were skeletal fluorosis and remaining was combined fluorosis. Table 1 depicts that the overall prevalence of fluorosis was $23.1 \%$ among the surveyed population. Males were affected more as compared to females. Prevalence of dental fluorosis was found to be more in male (13.6\%) as compared to female $(11.6 \%)$ while skeletal fluorosis found to be more in female as compared to male. Dental fluorosis (55\%) and skeletal fluorosis (38\%) were the most common type of fluorosis found among the surveyed inhabitants. Prevalence of dental fluorosis was more in 13-19 years age group $(34.6 \%)$ followed by $6-12$ years $(23.6 \%)$ while prevalence was lower in $>45$ years age groups. Prevalence of skeletal fluorosis was more common in above 45 years age group among both sexes while lower in the children (6-12). Prevalence of dental fluorosis was more in the students $(29.2 \%)$ whereas skeletal fluorosis was the highest among farmers $(35.1 \%)$. Table 2 indicates the highest number of dental fluorosis cases found in school para $(36.1 \%)$ followed by Sadakpara (32.8\%). Prevalence of genu varum was more in Nadigudaopara $(14.2 \%)$ followed by Sadakpara as compared to other paras. Kyphosis prevalence was more in Natkolkapara and Uparpara while multiple fluorosis deformities were observed in all paras but more prevalent in Sadakpara, Natkolkapara, and Uparpara. High prevalence was recorded in all surveyed hamlets, which may be associated with the highest fluoride level $(>7.0 \mathrm{ppm}$.) in the prime drinking water source. Natkolkapara had the highest prevalence of fluorosis even at low fluoride content in prime drinking water source.

\begin{tabular}{|c|c|c|c|c|}
\hline $\begin{array}{l}\text { Age } \\
\text { group }\end{array}$ & $\begin{array}{c}\text { Dental } \\
\text { fluorosis }\end{array}$ & $\begin{array}{l}\text { Combined } \\
\text { fluorosis }\end{array}$ & $\begin{array}{c}\text { Skeletal } \\
\text { fluorosis }\end{array}$ & Total \\
\hline $6-19$ & $166(29.0)$ & $15(2.6)$ & $3(0.5)$ & $184(32.1)$ \\
\hline $20-45$ & $45(6.7)$ & $13(1.9)$ & $66(9.9)$ & $124(18.5)$ \\
\hline $46>65$ & $0(0.0)$ & $1(0.3)$ & $78(29.7)$ & $79(30.0)$ \\
\hline Total & $211(12.6)$ & $29(1.7)$ & 147 (8.8) & $387(23.1)$ \\
\hline
\end{tabular}

$\chi^{2}=247 \cdot 7, \mathrm{df}=4, P \leq 0.0000001$

\begin{tabular}{lcccc}
\hline \multicolumn{3}{l}{$\begin{array}{l}\text { Table 2: Parawise prevalence of fluorosis and } \\
\text { water fluoride concentration of drinking water } \\
\text { sources }\end{array}$} \\
\hline Hamlets & $\begin{array}{c}\text { Total } \\
\text { population } \\
\text { of } \\
\text { surveyed }\end{array}$ & $\begin{array}{c}\text { Fluorosis } \\
\text { cases }\end{array}$ & $\begin{array}{c}\text { Prevalence } \\
\text { (proportion) }\end{array}$ & $\begin{array}{c}\text { Exposure to } \\
\text { mean water } \\
\text { fluoride } \\
\text { levels }\end{array}$ \\
\hline Aktagudapara & 46 & 7 & 15.2 & 6.8 \\
Charkholkapara & 51 & 7 & 13.7 & 4.4 \\
Kenduguda & 179 & 38 & 21.2 & 2.7 \\
Khalepara & 140 & 17 & 12.1 & 3.5 \\
Kotiyabhata & 160 & 11 & 6.9 & 1.3 \\
Nadigudaopara & 106 & 22 & 20.8 & 2.4 \\
Natkolkapara & 251 & 64 & 25.5 & 3.1 \\
Sadakpara & 287 & 94 & 32.8 & 6.7 \\
Schoolpara & 61 & 22 & 36.1 & 7.3 \\
Uparpara & 393 & 105 & 26.7 & 6.3 \\
Total & 1674 & 387 & 23.1 & 4.5 \\
\hline
\end{tabular}




\begin{tabular}{|c|c|c|c|c|c|c|c|c|}
\hline \multirow{2}{*}{$\begin{array}{l}\text { Range of } \\
\text { water fluoride } \\
\text { exposure (ppm) }\end{array}$} & \multicolumn{4}{|c|}{ Female } & \multicolumn{4}{|c|}{ Male } \\
\hline & $\begin{array}{l}\text { Combined } \\
\text { fluorosis }\end{array}$ & $\begin{array}{c}\text { Dental } \\
\text { fluorosis }\end{array}$ & $\begin{array}{l}\text { Skeletal } \\
\text { fluorosis }\end{array}$ & Total & $\begin{array}{l}\text { Combined } \\
\text { fluorosis }\end{array}$ & $\begin{array}{c}\text { Dental } \\
\text { fluorosis }\end{array}$ & $\begin{array}{l}\text { Skeletal } \\
\text { fluorosis }\end{array}$ & Total \\
\hline$>1.50-5.00$ & $2(0.5)$ & $18(4.6)$ & $15(3.8)$ & $35(8.8)$ & $5(1.2)$ & $29(8.8)$ & $12(3.2)$ & 46 (12.6) \\
\hline$>5.00$ & $3(1.2)$ & 79 (31.5) & $64(25.5)$ & $146(58.2)$ & $19(6.3)$ & $85(28.4)$ & $56(18.7)$ & $160(53.4)$ \\
\hline Total & $5(0.8)$ & $97(15.0)$ & 79 (12.2) & $181(28.0)$ & $24(3.6)$ & $114(17.2)$ & $68(10.2)$ & $206(31.0)$ \\
\hline
\end{tabular}

Fischer's exact test to male and female (for male $P=0.438$, female $P=0.500$ )

Prevalence of fluorosis was $>30 \%$ among primary school children where the fluorine content of water was $>7.0 \mathrm{ppm}$. A reason could be changing drinking water sources of the population, especially school going children. The association between water level of fluoride and sex of fluorosis affected persons was not significant as shown in Table 3. The fluoride content of various prime drinking water sources in surveyed paras was ranging from 0.1 to $7.30 \mathrm{ppm}$. A village had mainly 26 water sources and almost all inhabitants depend upon tube wells. Fluoride concentration was $>1.5 \mathrm{ppm}$ in $34.0 \%(10 / 29)$ of tube wells. Surveyed village had nine established defluoridation plant and out of those, five plants had fluoride level above $1.5 \mathrm{ppm}$.

\section{DISCUSSION}

The overall prevalence of fluorosis was $23.1 \%$, water fluoride levels varied from 0.1 to $7.3 \mathrm{ppm}$. These findings were confirmatory to the observations made by other researchers from other states, under similar conditions. ${ }^{[7-9]}$ The prevalence of overall dental fluorosis was $12.6 \%$, which is lower than other provinces in India. ${ }^{[7,10]}$ The prevalence of dental fluorosis in children was $23.6 \%$ and $34.6 \%$ in teenagers. Children and teenage group together contribute about $78.6 \%$ of total dental fluorosis cases. The prevalence of dental fluorosis declined after 45 years of age. Variable prevalence rates have been recorded from other Indian states namely Tamil Nadu, Haryana, Rajasthan and Uttar Pradesh. ${ }^{[8-11]}$ High prevalence in children and teenage group has been attributed to a higher concentration of fluoride in water. Additional factors such as nutritional status, climate, and individual susceptibility, and biological response, duration of exposure and frequency of fluoride intake may also have had played their role. ${ }^{[12]}$ Males had reported higher prevalence, analogous to observations made in UP, India ${ }^{[13]}$ and in contrast to findings from Kerala ${ }^{[14]}$ whereas, others found no gender differences. ${ }^{[10]}$ Differences in physical activity, food pattern, water consumption and mobility might have affected the outcome. In the present study, the prevalence of skeletal fluorosis is more among the farmers (35.1\%) followed by nonagricultural labor (16.0\%) while least in business, housewife, students, and service group. Some of the studies had reported a maximum incidence and severity of fluorosis in farmers and hardworking subjects only. ${ }^{[15,16]}$ This could be due to habitually carrying heavy load on the head, and these people are engaged in activities like digging and ploughing with elementary type of plough. All these put stress on the bone, and this also explains the preponderances of skeletal deformities in this group. A person engaged in light manual labor, housewife, and other group showed a lower incidence of bone lesion. Higher prevalence of fluorosis with increasing age was in concordance with findings by others researcher ${ }^{[12,17]}$ showing cumulative effect of longterm exposure. Common deformities of genu varum $(31.7 \%)$ genu vulgum $(4.1 \%)$ were also as reported by others too. ${ }^{[12,18]}$ Prevalence of skeletal fluorosis was nearly similar in both sexes while combined fluorosis was higher in male $(2.9 \%)$ as compare with female $(0.6 \%)$ in the present study. Other researchers also reported that males are affected more as compared to females. ${ }^{[18,19]}$ The relationship between the levels of fluoride in drinking water and fluorosis vary from place to place but in a study conducted in Rajasthan ${ }^{[7]}$ shows even at low level $(<1.5 \mathrm{ppm})$ the prevalence of skeletal fluorosis ranged from $6.1 \%$ to $9.5 \%$. As shown in Table 2 , the paras having highest fluoride levels in the prime drinking water sources also had the highest prevalence. Natkolkapara had the highest prevalence of fluorosis even though fluoride content in the prime drinking water was low. The prevalence of fluorosis was not found to be linked to water fluoride concentrations in all the paras. This may be explained by the habit of frequently changing the drinking water sources by the study subjects between the paras. It may also be due to the difference in occupation that may affect the amount of drinking water consumption by inhabitants of different paras. Moreover, the possible contribution of other factors related to the host also must be taken into account. Mean fluoride content in the hand pumps in the surveyed area was $4.50 \mathrm{ppm}$ with parawise variation.

\section{LIMITATIONS OF THE STUDY}

The subject showing sign of fluorosis was not assessed for serum and urine fluoride level and role of other factors such as diet, biological and duration of exposure could not be explored in the present study. Apart from these, the relationship between fluoride intoxication and ingestion of fluoride is dependent upon meteorological factors, e.g., high temperature, consumption of dirty water laden with suspended an impurity which was not ruled out.

\section{REFERENCES}

1. World Health Organization. Fluoride in Drinking-water: Background Document for Development of WHO Guidelines for Drinking-water Quality. Geneva: WHO; 2004.

2. Teotia SP, Teotia M. Endemic fluorosis in India: A challenging national health problem. J Assoc Physicians India 1984;32:347-52.

3. Carton RJ. Review of the 2006 United States National Research Council Report: Fluoride in drinking water. Fluoride 2006;39:163-72.

4. Wikipedia, the Free Encyclopedia. Fluoride Toxicity. Available from: http:// www.en.wikipedia.org/wiki/Fluoride_toxicity. [Last cited 2014 Aug 09].

5. Ayoob S, Gupta AK. Fluoride in drinking water: A review on the status and stress effects. Crit Rev Environ Sci Technol 2006;36:433-48. 
6. Pandey A. Prevalence of fluorosis in an endemic village in central India. Trop Doct 2010;40:217-9.

7. Choubisa SL. Endemic fluorosis in Southern Rajasthan, India. Fluoride 2001;34:61-70.

8. Yadav JP, Lata S. Urinary fluoride levels and prevalence of dental fluorosis in children of Jhajjar District, Haryana. Indian J Med Sci 2003; 57:394-9.

9. Janardhana RN, Dey S, Das K. Fluoride contamination in ground waters of Sonbhadra District, Uttar Pradesh, India. Curr Sci 2009; 96:7-10.

10. Saravanan S, Kalyani C, Vijayarani MP, Jayakodi P, Felix AJ, Nagarajan S, et al. India prevalence fluorosis among primary school children in rural areas of Chidambaram Taluk, Cuddalore District, Tamil Nadu. Indian J Community Med 2008;33:146-50.

11. Nanda RS. Observations on fluoride intake in Lucknow. J Indian Dent Assoc 1997; 144:177-81.

12. Shashi A, Kumar M, Bhardwaj M. Incidence of skeletal deformities in endemic fluorosis. Trop Doct 2008;38:231-3.

13. Ray SK, Ghosh S, Tiwari IC, Kaur P, Reddy DC, Nagchaudhuri J. Dental fluorosis in Ledhupur and Rustampur villages near Varanasi. Indian J Med Res 1983;77:112-8.
14. Gopalakrishnan P, Vasan RS, Sarma PS, Nair KS, Thankappan KR Prevalence of dental fluorosis and associated risk factors in Alappuzha district, Kerala. Natl Med J India 1999;12:99-103.

15. Choubisa SL, Choubisa L, Choubisa D. Osteo-dental fluorosis in relation to nutritional status, living habits, and occupation in rural tribal areas of Rajasthan, India. Res Rep Fluoride 2009;42:210-5.

16. Choubisa SL. Chronic fluoride intoxication (fluorosis) in tribes and their domestic animals. Int J Environ Stud 1999;56:703-16.

17. Bharati P, Rao M. Epidemiology of fluorosis in Dharwad district, Karnataka J Hum Ecol 2003;14:37-42.

18. Krishnamachari KA, Krishnaswamy K. Genu valgum and osteoporosis in an area of endemic fluorosis. Lancet 1973;2:877-9.

19. Watanabe T, Kondo T, Asanuma S, Ando M, Tamura K, Sakuragi S, et al Skeletal fluorosis from indoor burning of coal in Southwestern China Fluoride 2000;33:135-9.

How to cite this article: Gitte SV, Sabat R, Kamble K. Epidemiological survey of fluorosis in a village of Bastar division of Chhattisgarh state, India. Int J Med Public Health 2015;5:232-5.

Source of Support: Nil, Conflicts of Interest: None declared. 